\title{
The possible importance of income and education as
}

\section{covariates in cohort studies [version 1; peer review: 1}

\section{approved, 1 approved with reservations]}

\author{
Norman Temple \\ Centre for Science, Athabasca University, Alberta, Canada
}

\author{
V1 First published: 07 Sep 2015, 4:690 \\ https://doi.org/10.12688/f1000research.6929.1 \\ Latest published: 18 May 2016, 4:690 \\ https://doi.org/10.12688/f1000research.6929.2
}

\section{Abstract}

Background: Many cohort studies have been carried out that have provided information on the relationship between diet and healthrelated outcomes. Omission of important covariates during multivariate analysis may give rise to error due to residual confounding. A possibly important covariate is socioeconomic status (SES) as this is related to both diet and health.

Methodology: An analysis was carried out of 76 randomly selected papers from 66 cohort studies. The papers covered many dietary variables and a wide variety of diseases/health-related outcomes. The cohort studies were carried out in many different locations and the subjects varied widely in age.

Results: Approximately two-thirds of the papers (65.8\%) used at least one measure of SES as a covariate. Education was used most often (60.5\% of papers), followed by income (14.4\%) and social class (2.6\%). More than one measure of SES was used in $11.8 \%$ of papers.

Conclusions: Failure to include income (or another measure of present SES, such as occupation) may therefore be a common source of error in cohort studies. Failure to include education may be particularly important as it is likely to be a weaker measure of present SES than is income. There is a need for more research on this question. SES in childhood is almost never included in multivariate analysis in cohort studies carried out on adults. This could also play a significant role in disease risk in middle age or later. Very little is known regarding whether this is also a source of residual confounding.

Keywords

Cohort studies, socioeconomic status, covariates

\section{Open Peer Review}

Approval Status

1

2

\section{version 2}

(revision)

18 May 2016

version 1

07 Sep 2015

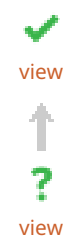

\section{view}

1. Tord Finne Vedøy, Norwegian Institute for

Alcohol and Drug Research, Oslo, Norway

2. Silvano Gallus, IRCCS-Mario Negri Institute

for Pharmacological Research, Milan, Italy

Any reports and responses or comments on the article can be found at the end of the article. 
Corresponding author: Norman Temple (normant@athabascau.ca)

Competing interests: No competing interests were disclosed.

Grant information: The author(s) declared that no grants were involved in supporting this work.

Copyright: ( 2015 Temple N. This is an open access article distributed under the terms of the Creative Commons Attribution License, which permits unrestricted use, distribution, and reproduction in any medium, provided the original work is properly cited.

How to cite this article: Temple N. The possible importance of income and education as covariates in cohort studies [version 1; peer review: 1 approved, 1 approved with reservations] F1000Research 2015, 4:690 https://doi.org/10.12688/f1000research.6929.1

First published: 07 Sep 2015, 4:690 https://doi.org/10.12688/f1000research.6929.1 


\section{Introduction}

Socioeconomic status (SES) is related to diet and health. It is well established that affluent people have superior health compared to poorer people ${ }^{1}$. A major part of the explanation for this is that people with high SES generally follow a healthier lifestyle ${ }^{1}$. Of particular note, many studies have reported that people with a higher SES consume a more nutritious diet². This pattern has been consistently reported in the USA, Canada, and many European countries, and is seen with different indicators of SES - education, income, and occupation.

This suggests that income, or other indicators of SES, may be a relevant factor in cohort studies. It follows, therefore, that failure to include SES in multivariate analysis of findings from cohort studies may be a source of error due to residual confounding. The potential importance of this was shown by an analysis of data from the British Women's Heart and Health Study. Adjusting for a range of factors that indicate SES, both those in childhood and adulthood, attenuated the relationship between the plasma concentration of vitamins $\mathrm{C}$ and $\mathrm{E}$ and risk of coronary heart disease (CHD) in adults aged over 60 years $^{3,4}$.

The analysis described here was carried out in order to investigate the extent of this potential source of error.

\section{Methods}

An analysis was carried out of papers that reported the findings of cohort studies. The main inclusion criteria were, first, the papers were published in journals in the year 2000 or later, and, second, they reported findings on the relationship between dietary intake and health-related outcomes, such as body weight or disease. The papers were found using two main search strategies: (1) they were cited in various meta-analyses; and (2) by searching journals that cover the areas of nutrition, health, and medicine but with the search restricted to issues published in late 2013. A list of all papers used in this study is included in the Supplementary material.

Each paper was studied and key information was extracted. In particular, a record was made indicating whether the risk ratios were adjusted for factors that indicate SES, such as education and income. Where available, information was also extracted that reported associations between SES and dietary variables (e.g., whether study subjects with more education consumed more fish). In addition, for comparative purposes a record was kept of whether alcohol, physical activity, and hypertension were included as covariates.

Many cases were found where two or more papers were based on the same cohort study. In those cases each paper was evaluated. However, only one of the papers was included here unless, with respect to the covariates that are the focus of this paper, the papers used different covariates in the multivariate analysis. Papers were also included if they contained relevant information on the association between SES and dietary variables. After these exclusions and inclusions 76 papers from 66 cohort studies were included in the final analysis. Ten were published in the years 2000 to 2003,15 during 2004 to 2007, 27 during 2008 to 2012, and 24 during 2013. The study is therefore based on a convenience sample of cohort studies rather than a systematic review. Nevertheless, because of the large number of cohort studies included, the findings are likely to be representative of cohort studies published in recent years.

\section{Results}

The findings reported here are based on 66 cohort studies of which 52 were carried out on adults and 14 on children (age $<18$ years). They were carried out in the USA (30), Europe (28), Asia (5), and Canada (3).

The analysis included 76 papers. They covered a wide variety of diseases/health-related outcomes, including body weight or another measure of adiposity (25), cancer (21), type 2 diabetes (5), and all-cause mortality (16). Cardiovascular disease was studied in 33 papers, of which 19 looked at all forms of CVD combined, 13 at CHD, one at both CVD and CHD, and two at stroke. These 76 papers covered many aspects of the diet, including sugar-sweetened beverages (18), diet patterns (14), multivitamin supplements (8), fish (7), milk (7), sodium (6), and meat (4). The great majority of the papers covered only one dietary variable; the main exception was studies on beverages where different beverages were often included in the same paper. Physical activity was included as a covariate in 56 of the 76 papers $(73.7 \%)$, alcohol in 43 of the 61 papers on adults $(70.5 \%)$, and hypertension or blood pressure in 21 of the 33 papers on CVD (63.6\%). At least one measure of SES was included as a covariate in 50 of the 76 papers $(65.8 \%)$. Education was by far the most common $(60.5 \%)$, followed by income $(14.4 \%)$ and social class $(2.6 \%)$. Several papers $(11.8 \%)$ included more than one measure of SES.

Papers based on studies of children used a measure of SES with a similar frequency to those on adults. Parental SES was used in those studies.

Many of the papers reviewed here reported on the association between SES and diet. In general, people with more education consumed a diet that is associated with better health. This includes more fish ${ }^{5-7}$, less meat ${ }^{8,9}$, as well as a healthier overall dietary pattern $^{10-13}$. In addition, some papers reported that those with more education consume more sugar-sweetened beverages ${ }^{14,15}$, more fruit juice $^{14,16}$, and more sodium ${ }^{17,18}$. A particularly clear trend is the association between education and consumption of multivitamin supplements ${ }^{19-24}$.

A small number of the papers reported on the association between income and diet. Consistent with the above findings higher income is associated with eating more fish ${ }^{6,7}$ and a healthier overall dietary pattern $^{12}$.

\section{Discussion}

The methodology used here has strengths and weaknesses. The papers analyzed were mostly published in the last few years (51 of the 77 papers appeared in 2008 or later while the remainder appeared between 2000 and 2008). They cover a wide range of dietary components and outcomes. Sixty-four of the 66 cohort studies were carried out in the USA, Canada, Europe, or Japan. The findings are therefore likely to be representative of cohort studies 
published in recent years that investigated the relationship between diet and risk of a wide variety of diseases and health-related outcomes. However, as the papers analyzed were randomly selected, there may be a degree of selection bias.

Approximately two-thirds of the papers (65.8\%) used at least one measure of SES as a covariate. The most commonly used one was education (used in $60.5 \%$ of papers), followed by income (14.4\%) and social class (2.6\%). Some papers (11.8\%) used more than one measure of SES. The frequency of inclusion of SES as a covariate is similar to that seen for the other covariates that were looked at here (73.7\% for physical activity, $70.5 \%$ for alcohol in papers on adults, and $63.6 \%$ for hypertension or blood pressure in papers on CVD).

Many of the papers provided information on the relationship between SES and diet. The findings reveal that people with more education typically consume a healthier diet. However, with some aspects of the diet the opposite trend was seen: several papers reported that those with more education consume more sugar-sweetened beverages and more sodium. They also consume more multivitamin supplements. Income also seems to be positively associated with diet quality; however, only a handful of papers provided information on this. That persons with a higher SES consume a generally more nutritious diet is consistent with previous studies (2). Likewise, previous studies have also consistently reported that users of multivitamin supplements are generally better educated ${ }^{25-27}$.

The findings reported here indicate that failure to include SES in multivariate analysis of cohort studies may be a source of error due to residual confounding. There are several ways by which this might happen. For example, in studies of CVD, error may occur if people of higher SES have better access to the health-care system and are therefore more likely to be screened for risk factors for CVD and to then receive better quality preventive treatment (such as diagnosis and treatment of hypertension). Similarly, error may arise in studies where body weight is the end-point if those of higher SES make greater efforts than those of lower SES to avoid excess weight gain. Conversely, lower SES may increase the risk of disease via psychological pathways, such as by raising the level of stress or by inducing feelings of disempowerment.

In some cohort studies subjects are fairly similar with respect to SES. For example, the Physicians' Health Study included only male physicians $^{28}$. In such cases failure to adjust for SES is unlikely to lead to a significant error. However, in the large majority of cohort studies the subjects have a fairly wide variation in level of education and income.

Education, income, and social class (or occupation) has each been used as a covariate in the analysis of results from cohort studies. Education has been used far more often than the other two indicators of SES. While all three are closely associated with SES, they are quite distinct. For example, many people have a relatively poor education but still achieve a high income. This often occurs by marriage or by becoming a successful businessperson. Conversely, a person may have a college education but end up with a low income.
It follows, therefore, that income (which indicates SES at the present time) may exert more influence on health and behavior than does education (which may have ceased 20 years or more before the cohort study started). Support for this possibility came from an Australian analysis that concluded that income was more strongly associated with diet than was education ${ }^{29}$. These findings indicate, therefore, that as only a small minority of cohort studies $(14.4 \%$ of the publications) included income as a covariate, this may be a significant source of error due to residual confounding.

A related question is SES in childhood as this could play a significant role in disease risk in middle age or later. This was suggested by findings from a British cohort study ${ }^{3,4}$. Adjusting for a range of factors that indicate SES, both those in childhood and adulthood, attenuated the relationship between the plasma concentration of both vitamins $\mathrm{C}$ and $\mathrm{E}$ and risk of CHD in adults aged over 60 . With the exception of that study, I am unaware of any other cohort study that has examined the relationship between SES in childhood and disease risk in adults older than age 50.

As cohort studies vary widely in such features as the country where they are conducted, the age and gender of subjects, the dietary variables being studied, and the health outcomes being investigated, it is likely that the magnitude of the error caused by residual confounding will also be highly variable. More research effort is required to determine the extent to which failure to adjust for SES across the lifecycle (as well as of other covariates) is a source of error in cohort studies.

Another potentially important covariate is growth in the fetal period and early infancy. Fetal development, as indicated by birthweight, as well as the rate of weight gain in early childhood, are predictors of risk of developing heart disease and type 2 diabetes 40 or 50 years later ${ }^{30}$. While these variables may be only weakly related to SES, they are relevant here as they again underscore how diet, lifestyle, and SES in childhood (or even before birth) may be associated with disease risk decades later.

In conclusion, many cohort studies may have residual confounding caused by the failure to adjust for key covariates. Little attention seems to have been paid to this possible source of significant error. Of particular concern is the question of SES: roughly one third of papers have not included any measure of SES among the covariates. Education was used as the measure of SES far more often than income. However, education is likely to be a weaker measure of present SES than is income. There is a need for more research on the extent to which failure to include income (or another measure of present SES, such as occupation) leads to error in cohort studies.

\section{Competing interests}

No competing interests were disclosed.

\section{Grant information}

The author(s) declared that no grants were involved in supporting this work. 


\section{Supplementary material \\ Papers used as a source of information for this study.}

Papers with the same number but different letters (e.g., 2a and $2 \mathrm{~b}$ ) indicate that the same cohort study contributed two separate papers

Click here to access the data.

1. Di Cesare M, Khang $\mathrm{YH}$, Asaria $\mathrm{P}$, et al:: Inequalities in non-communicable diseases and effective responses. Lancet. 2013; 381(9866): 585-597. PubMed Abstract | Publisher Full Text

2. Darmon N, Drewnowski A: Does social class predict diet quality? Am J Clin Nutr. 2008; 87(5): 1107-1117 PubMed Abstract

3. Lawlor DA, Davey Smith G, Kundu D, et al: Those confounded vitamins: what can we learn from the differences between observational versus randomised trial evidence? Lancet. 2004; 363(9422): 1724-1727. PubMed Abstract | Publisher Full Text

4. Lawlor DA, Ebrahim S, Kundu D, et al: Vitamin C is not associated with coronary heart disease risk once life course socioeconomic position is taken into account: prospective findings from the British Women's Heart and Health Study. Heart. 2005; 91(8): 1086-1087.

PubMed Abstract | Publisher Full Text | Free Full Text

5. de Goede J, Geleijnse JM, Boer JM, et al.: Marine (n-3) fatty acids, fish consumption, and the 10 -year risk of fatal and nonfatal coronary heart disease in a large population of Dutch adults with low fish intake. $J$ Nutr. 2010; 140(5): 1023-1028.

PubMed Abstract | Publisher Full Text

6. Tomasallo $\mathrm{C}$, Anderson $\mathrm{H}$, Haughwout $\mathrm{M}$, et al.: Mortality among frequent consumers of Great Lakes sport fish. Environ Res. 2010; 110(1): 62-69. PubMed Abstract | Publisher Full Text

7. Folsom AR, Demissie Z: Fish intake, marine omega-3 fatty acids, and mortality in a cohort of postmenopausal women. Am J Epidemiol. 2004; 160(10): 1005-1010. PubMed Abstract | Publisher Full Text

8. Sinha R, Cross AJ, Graubard $\mathrm{BI}$, et al.: Meat intake and mortality: a prospective study of over half a million people. Arch Intern Med. 2009; 169(6): 562-571. PubMed Abstract | Publisher Full Text | Free Full Text

9. Rohrmann S, Overvad K, Bueno-de-Mesquita HB, et al.: Meat consumption and mortality--results from the European Prospective Investigation into Cancer and Nutrition. BMC Med. 2013; 11: 63. PubMed Abstract | Publisher Full Text | Free Full Text

10. Boggs DA, Rosenberg L, Rodríguez-Bernal CL, et al.: Long-term diet quality is associated with lower obesity risk in young African American women with normal BMI at baseline. J Nutr. 2013; 143(10): 1636-1641. PubMed Abstract | Publisher Full Text | Free Full Text

11. Wengreen H, Munger RG, Cutler A, et al:: Prospective study of Dietary Approaches to Stop Hypertension- and Mediterranean-style dietary patterns and age-related cognitive change: the Cache County Study on Memory, Health and Aging. Am J Clin Nutr. 2013; 98(5): 1263-1271. PubMed Abstract | Publisher Full Text | Free Full Text

12. Parrott MD, Shatenstein B, Ferland G, et al.: Relationship between diet quality and cognition depends on socioeconomic position in healthy older adults. J Nutr. 2013; 143(11): 1767-1773.

PubMed Abstract | Publisher Full Text

13. Velie EM, Schairer C, Flood A, et al:: Empirically derived dietary patterns and risk of postmenopausal breast cancer in a large prospective cohort study. $A m$ J Clin Nutr. 2005; 82(6): 1308-1319. PubMed Abstract

14. Vanselow MS, Pereira MA, Neumark-Sztainer D, et al:: Adolescent beverage habits and changes in weight over time: findings from Project EAT. Am J Clin Nutr. 2009; 90(6): 1489-1495.

PubMed Abstract | Publisher Full Text

15. Palmer JR, Boggs DA, Krishnan S, et al:: Sugar-sweetened beverages and incidence of type 2 diabetes mellitus in African American women. Arch Intern Med. 2008; 168(14): 1487-1492.

PubMed Abstract | Publisher Full Text | Free Full Text
16. Johnson L, Mander AP, Jones LR, et al.: Is sugar-sweetened beverage consumption associated with increased fatness in children? Nutrition. 2007; 23(7-8): 557-563.

PubMed Abstract | Publisher Full Text

17. Cohen HW, Hailpern SM, Fang J, et al:: Sodium intake and mortality in the NHANES II follow-up study. Am J Med. 2006; 119(3): 275.e7-14.

PubMed Abstract | Publisher Full Text

18. Cohen HW, Hailpern SM, Alderman MH: Sodium intake and mortality follow-up in the Third National Health and Nutrition Examination Survey (NHANES III). J Gen Intern Med. 2008; 23(9): 1297-1302.

PubMed Abstract | Publisher Full Text | Free Full Text

19. Li K, Kaaks R, Linseisen J, et al.: Vitamin/mineral supplementation and cancer, cardiovascular, and all-cause mortality in a German prospective cohort (EPICHeidelberg). Eur J Nutr. 2012; 51(4): 407-413. PubMed Abstract | Publisher Full Text

20. Mursu J, Robien K, Harnack LJ, et al:: Dietary supplements and mortality rate in older women: the lowa Women's Health Study. Arch Intern Med. 2011; 171(18): older women: 16253.

1625-1633.
PubMed Abstract | Publisher Full Text | Free Full Text

21. Neuhouser ML, Wassertheil-Smoller S, Thomson C, et al:: Multivitamin use and risk of cancer and cardiovascular disease in the Women's Health Initiative cohorts. Arch Intern Med. 2009; 169(3): 294-304. PubMed Abstract | Publisher Full Text | Free Full Text

22. Park SY, Murphy SP, Wilkens LR, et al:: Multivitamin use and the risk of mortality and cancer incidence: the multiethnic cohort study. Am J Epidemiol. 2011; 173(8): 906-914.

PubMed Abstract | Publisher Full Text | Free Full Text

23. Rautiainen S, Akesson A, Levitan EB, et al:: Multivitamin use and the risk of myocardial infarction: a population-based cohort of Swedish women. Am J Clin Nutr. 2010; 92(5): 1251-1256.

PubMed Abstract | Publisher Full Text

24. Watkins ML, Erickson JD, Thun MJ, et al.: Multivitamin use and mortality in a large prospective study. Am J Epidemiol. 2000; 152(2): 149-162. PubMed Abstract | Publisher Full Text

25. Radimer K, Bindewald B, Hughes J, et al.: Dietary supplement use by US adults: data from the National Health and Nutrition Examination Survey, 1999-2000. Am J Epidemiol. 2004; 160(4): 339-349. PubMed Abstract | Publisher Full Text

26. Millen AE, Dodd KW, Subar AF: Use of vitamin, mineral, nonvitamin, and nonmineral supplements in the United States: The 1987, 1992, and 2000 National Health Interview Survey results. J Am Diet Assoc. 2004; 104(6): 942-950.

PubMed Abstract | Publisher Full Text

27. Satia-Abouta J, Kristal AR, Patterson RE, et al.: Dietary supplement use and medical conditions: the VITAL study. Am J Prev Med. 2003; 24(1): 43-51. PubMed Abstract | Publisher Full Text

28. Hshieh TT, Petrone AB, Gaziano JM, et al:: Nut consumption and risk of mortality in the Physicians' Health Study. Am J Clin Nutr. 2015; 101(2): 407-412.

PubMed Abstract | Publisher Full Text | Free Full Text

29. Turrell G, Hewitt B, Patterson C, et al.: Measuring socio-economic position in dietary research: is choice of socio-economic indicator important? Public Health Nutr. 2003; 6(2): 191-200.

PubMed Abstract | Publisher Full Text

30. Barker DJP: The developmental origins of chronic disease in later life. In: Temple NJ, Wilson T, Jacobs DR, eds. Nutritional Health: Strategies for Disease Prevention, 3rd ed. New York: Humana Press, 2012; 59-83. Publisher Full Text 


\section{Open Peer Review}

\section{Current Peer Review Status:}

\section{Version 1}

Reviewer Report 12 May 2016

https://doi.org/10.5256/f1000research.7462.r13500

(C) 2016 Gallus S. This is an open access peer review report distributed under the terms of the Creative Commons Attribution License, which permits unrestricted use, distribution, and reproduction in any medium, provided the original work is properly cited.

\section{Silvano Gallus}

Department of Epidemiology, IRCCS-Mario Negri Institute for Pharmacological Research, Milan, Italy

This is a well-written manuscript providing information on the use of socioeconomic status (SES) measures as covariates in 76 papers from 66 cohort studies. The study is interesting and original. I only have a few minor points which could improve the presentation of findings:

1. The objectives of the study may be clarified in the background or methods sections of the abstract;

2. In the conclusions of the abstract, I suggest to delete the term "therefore" ( $2^{\text {nd }}$ line of the Conclusions);

3. In population-based cohort studies, income may represent a major problem, given the likely high nonresponse rate. For example, in a European cross-sectional study I conducted in 2010 on more than 18,000 European adults, $22 \%$ of participants did not provide information on income, and only a negligible proportion of subjects did not provide information on education. Also for this reason, education (or alternatively occupation) may be considered a more appropriate proxy of SES than income. This issue may be further addressed both in the abstract and in the main text.

Competing Interests: No competing interests were disclosed.

\section{I confirm that I have read this submission and believe that I have an appropriate level of expertise to confirm that it is of an acceptable scientific standard.}

Reader Comment 23 Sep 2017

Dr. Sindhu B.M., Dr. D. Y. Patil Medical College, Hospital and Research Center, India Respected Sir,

I have a doubt regarding this. I request you to throw some light on this.. 
When people dont respond to a question (eg: income/education) in a study, should we take them as 'non-responders' and not analyse their data? Or analyse their data also?

Competing Interests: No competing interests were disclosed.

Reviewer Report 18 November 2015

https://doi.org/10.5256/f1000research.7462.r11155

(c) 2015 Vedøy T. This is an open access peer review report distributed under the terms of the Creative Commons Attribution License, which permits unrestricted use, distribution, and reproduction in any medium, provided the original work is properly cited.

\section{Tord Finne Vedøy}

Norwegian Institute for Alcohol and Drug Research, Oslo, Norway

This paper is an important reminder that SES is a crucial factor to consider when doing research on health related lifestyle issues. However, I do have some comments of minor importance.

First, in the first paragraph of the introduction the author emphasizes the role of a nutritious diet for a health lifestyle. Although I understand that the paper focuses on nutrition, it could be noted that smoking still is one of the largest, if not the largest, single cause of death and disease in most developed countries. For the same reasons it might be a good idea to mention in the title that the focus of the paper is nutrition.

Second, the author should make explicit what is meant by "cohort studies". Does this refer to panel-studies, age-period-cohort studies or both?

Third, the transition from the first to the second paragraph in the introduction seems wanting. As I read it, it is the pattern ("that people with a higher SES consume a more nutritious diet") that "suggests that income, or other indicators of SES, may be a relevant factor in cohort studies". However, if cohort is to be an important factor, the temporal or historical dimension of the pattern should be emphasized.

Fourth, the discussion of the relative importance of different measures of SES on health could be more nuanced. While there may be good reasons for using income rather than education as a measure of SES, especially in matters of consumption, education has certain characteristics which income lacks. For example, education is stable throughout the lifespan and provides individuals with certain abilities related to learning and thinking which are important in matters of health. These ideas has been discussed by for example Cutler and Lleras-Muney (2010).

\section{References}

1. Cutler DM, Lleras-Muney A: Understanding differences in health behaviors by education.J Health 
Econ. 2010; 29 (1): 1-28 PubMed Abstract | Publisher Full Text

Competing Interests: No competing interests were disclosed.

I confirm that I have read this submission and believe that I have an appropriate level of expertise to confirm that it is of an acceptable scientific standard, however I have significant reservations, as outlined above.

Author Response 08 May 2016

Norman Temple, Athabasca University, Alberta, Canada

I thank Dr Vedøy for his helpful comments. I have made edits to the paper based on those comments.

Competing Interests: No competing interests were disclosed.

The benefits of publishing with F1000Research:

- Your article is published within days, with no editorial bias

- You can publish traditional articles, null/negative results, case reports, data notes and more

- The peer review process is transparent and collaborative

- Your article is indexed in PubMed after passing peer review

- Dedicated customer support at every stage

For pre-submission enquiries, contact research@f1000.com 